\title{
PERAN ETIKA BISNIS DAN KUNCI SUKSES DALAM PEMASARAN SYARI'AH
}

\author{
Akhmad Yusup \\ Program Studi Hukum Ekonomi Syari'ah Fakultas Syari'ah, Universitas Islam Bandung, \\ Indonesia. Email : akhyuss91@gmail.com
}

\begin{abstract}
ABSTRAK
Perkembangan Revolusi Industri 4.0 dan Society 5.0 memicu dampak positif bagi pelaku usaha dan masyarakat diberbagai sektor industri, khususnya pada sektor ekonomi dalam kegiatan berbisnis. Akan tetapi, tidak dipungkiri dengan adanya hal tersebut ternyata merubah esensi daripada hakikat praktik bisnis, seperti halnya didalam pemasaran yang diajarkan oleh Islam, walaupun banyak cara untuk menyelesaikanya. Studi ini mendiskusikan fenomena etika bisnis para pelaku usaha dan masyarakat dalam menjalankan praktik bisnis yang terkadang mengabaikan prinsip-prinsip syari'ah. Selain itu, studi ini juga akan membahas beberapa kunci sukses dalam pemasaran syari'ah. Kajian ini dibangun dengan metode penelitian kualitatif melalui dukungan literatur jurnal, buku, media berita online, dan catatan resmi lainnya yang memiliki tingkat relevansi yang sesuai dengan pembahasan yang dibutuhkan. Sumber-sumber akan ditelaah untuk mengkontruksi realita dan memahami maknanya, kemudian dilakukan analisis, sehingga dapat diketahui kesesuaian data, kelayakan norma, dan gagasan-gagasan normatif yang baru. Kajian ini menyimpulkan dengan berkembangnya sektor ekonomi dalam kegiatan berbisnis pada era Revolusi Industri 4.0 dan Society 5.0, terdapat faktor-faktor yang memengaruhi perilaku etis dalam Islam, dan etika perilaku para produsen dan konsumen. Selain itu, terdapat kunci kesuksesan yang diajarkan oleh Rasulullah Saw sebagai modal penting untuk memenangkan persaingan di era pemasaran modern.
\end{abstract}

Kata-kata kunci : Etika Bisnis; Pemasaran Syari'ah; Kunci Sukses

\begin{abstract}
The development of the Industrial Revolution 4.0 and Society 5.0 triggered a positive impact on businesses and public in various industrial sectors, especially in the economic sector in business activities. However, it is undeniable that this has changed the essence of the nature of business practices, as in marketing taught by Islam, although there are many ways to solve them. This study discusses the phenomenon of business ethics among business people and the community in carrying out business practices that sometimes ignore sharia principles. In addition, this study will also discuss several keys to success in sharia marketing. This study was built with qualitative research methods through the support of journal literature, books, online news media, and other official records that have a level of relevance in accordance with the discussion needed. The sources will be examined to construct reality and understand its meaning, then an analysis is carried out, so that data suitability, norm feasibility and new normative ideas can be identified. This study concludes with the development of the economic sector in business activities in the era of the Industrial Revolution 4.0 and Society 5.0, there are factors that influence ethical behaviour in Islam, and
\end{abstract}


ethical behaviour of producers and consumers. In addition, there are keys to success taught by Rasulullah Saw as important capital to win the competition in the era of modern marketing.

Keywords: Business Ethics; Shariah Marketing; Keys to Success

\section{PENDAHULUAN}

Islam mengajarkan segala bentuk hal sebagai petunjuk kehidupan, termasuk hubungan manusia dengan pencipta (muammalah ma'a Allah), dan manusia dengan manusia (muammalah ma'a nnaas) dalam interaksi sosial yang sesuai dengan syariat Islam, karena sebagai makhluk sosial, manusia tidak bisa hidup sendiri. Sebagai manusia, kebutuhan saling membutuhkan satu sama lain sangat diperlukan untuk melanjutkan rantai kehidupan, seperti halnya penjual dan pembeli, produsen dan konsumen. Selain itu, hal yang diperlukan manusia untuk melanjutkan rantai kehidupan adalah tidak terlepas dari berbagai macam aktifitas ekonomi, seperti produksi, distribusi, konsumsi, ekspor ataupun impor yang memiliki menggambarkan hubungan manusia dengan pencipta dan sesama manusia (Al-Qaradhawi, 1997).

Di tengah ketatnya persaingan ekonomi global yang sudah banyak mempengaruhi perilaku manusia dalam menjalankan berbagai aktifitas ekonomi, seperti yang terjadi pada era Revolusi Industri 4.0 dan Society 5.0, yaitu pencampuran aktifitas manusia dengan perkembangan teknologi yang ada pada zaman ini. Sehingga, masing-masing pelaku aktifitas ekonomi dan khususnya produsen atau penjual melakukan segala sesuatu untuk mempertahankan eksistensi bisnisnya untuk menarik perhatian konsumen dengan berbagai jenis metode pemasaran. Akan tetapi, pola produsen atau penjual dalam mengembangkan bisnisnya dan menarik perhatian konsumen, terkadang mengabaikan etika bisnis yang diajarkan oleh Islam. Seperti halnya Islam menjelaskan dan mengajarkan kepada manusia dalam berbisnis agar tidak hanya menghasilkan keuntungan yang sifatnya materi semata, tetapi juga keberkahan dan memenuhi aturan yang ditetapkan oleh Allah Swt (Asnawi, 2017).

Konsep etika bisnis sudah dijelaskan didalam Islam, yaitu "khuluq" yang mengacu pada nilai moral dan nilai-nilai positif yang berupa: khoir (kebaikan); birr (kebajikan); qist (kesetaraan); 'adl (keseimbangan dan keadilan); haqq (kebenaran dan baik); ma'ruf (kebaikan, disepakati); dan 
taqwa (keshalehan) (Asnawi, 2017). Oleh karena itu, sebagai Muslim yang baik harus mencerminkan etika yang sesuai dengan ajaran Islam.

Jika melihat dari segi akademik, banyak sekali literatur yang sudah membahas dan mengupas tentang etika bisnis, namun sejauh ini sedikit paper yang membahas tentang peran etika bisnis dan kunci sukses dalam pemasaran syari'ah. Sedangkan, banyak pakar bisnis dan ahli agama yang mengemukakan bahwa peranan etika bisnis khususnya etika bisnis syari'ah sangatlah penting dalam menjalankan berbagai aktifitas ekonomi dan bisnis, bahkan dalam segi pemasaran syari'ah. Kajian ilmiah ini lahir dari ketidaksesuaian antara konsep dan mekanisme etika bisnis yang diajarkan oleh Islam dengan kejadian dilapangan dan beberapa kasus dari para pelaku bisnis yang menghalalkan segala cara pemasaran untuk menarik konsumen, sehingga peneliti mengangkatnya menjadi sebuah permasalahan dan secara komprehensif membahasnya dalam bentuk judul "Peran Etika Bisnis dan Kunci Sukses Dalam Pemasaran Syari'ah". Tujuannya adalah untuk memberikan gambaran kepada palaku bisnis untuk lebih memperhatikan etika dalam berbisnis dan memberikan gambaran kunci sukses dalam pemasaran syari'ah yang telah diajarkan oleh Rasulullah Saw.

\section{METODE PENELIITIAN}

Penelitian ini menggunakan metode deskriptif-kualitatif yang bertujuan untuk mendapatkan hasil penelitian yang seobjektif mungkin dengan menggunakan jenis library research, yaitu didapat dari data sekunder berupa buku-buku dan artikel-artikel ilmiah yang relevan dengan kajian ini. Selain itu, Teknik analisis data yang digunakan adalah analisis kualitatif dengan pendekatan pendekatan normatif yang mencakup reduksi data, penyajian data dan sampai kepada kesimpulan.

\section{HASIL PENELITIAN DAN PEMBAHASAN}

\section{Revolusi Industri 4.0 dan Society 5.0 beserta Dampaknya}

Saat ini, istilah perkembangan teknologi dan informasi sering dikenal dengan sebutan era Revolusi Industri 4.0. yang ditandai dengan beragam aktifitas dan pekerjaan manusia dibantu oleh kecanggihan teknologi dan informasi (Mumtaha \& Khoiri, 2019). Revolusi Industri 1.0 merupakan revolusi pertama yang dipelopori oleh Inggris dan terjadi pada akhir abad 
17 atau tepatnya sekitar tahun 1800-1900. Hingga saat ini Revolusi Industri sudah berkembang sampai dengan 4.0. Adapun tahapan perkembangan revolusi industri terdapat pada Gambar 1.

Gambar 1. Tahapan Perkembangan Revolusi Industri 1.0 sampai 4.0 (The Fourt Industria Revolution)

\section{THE}

FOURTH

INDUSTRIAL

REVOLUTION

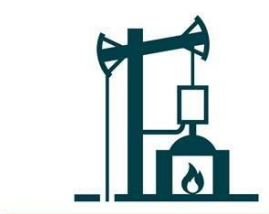

INDUSTRY 1.0

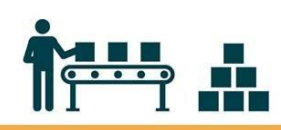

INIUSTRY 2.0

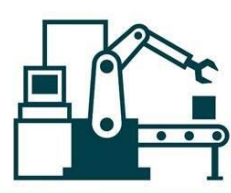

INDUSTRY 3.0

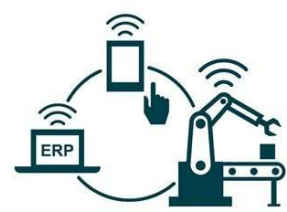

INDUSTRY 4.0

Industry 4.0 adalah industri yang menggabungkan teknologi otomasi dengan teknologi cyber. Selain itu, ini merupakan tren otomatisasi dan pertukaran data dalam teknologi manufaktur, termasuk sistem cyber-fisik, Internet of Things (IoT), komputasi awan dan komputasi kognitif.

Setelah Inggris mempelopori perkembangan revolusi industri, kemudian disusul oleh Jepang dengan meluncurkan roadmap yang berkaitan dengan perubahan perilaku kebutuhan manusia pada saat ini yang dikenal dengan sebutan istilah Society 5.0. Jika dalam pembahasan Revolusi Industri 4.0 menjadikan teknologi dan informasi sebagai fokus objek untuk membantu pergerakan manusia, maka Society 5.0 tidak seperti itu, akan tetapi lebih kepada pembahasan manusia yang tidak hanya menjadi objek, melainkan berperan aktif dalam mencapai sebuah tujuan (Mumtaha \& Khoiri, 2019). Berikut digambarkan perkembangan Society 5.0 pada Gambar 2. 
Gambar 2. Tahapan Perkembangan Society 5.0

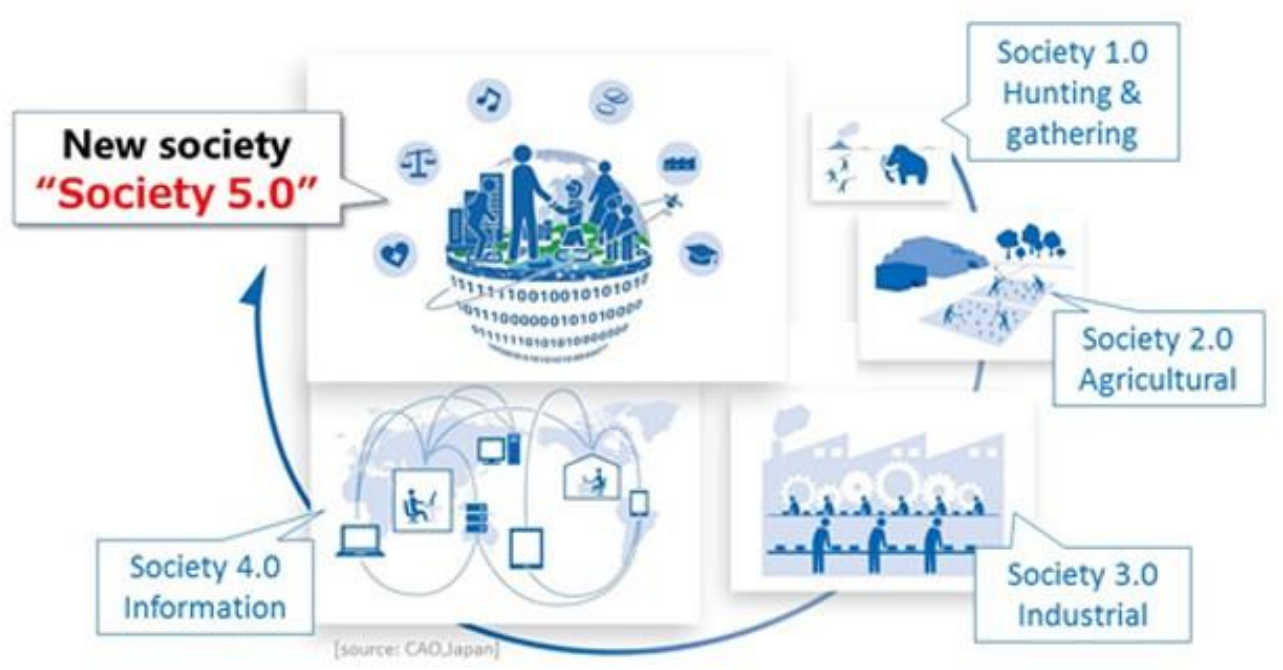

Di sisi lain, Perkembangan Revolusi Industri 4.0 dan Society5.0 telah mempengaruhi dan memberikan banyak dampak pada kehidupan masyarakat. Setelah adanya perkembangan tersebut, masyarakat lebih senang mencampurkan teknologi dan informasi untuk kemudahan aktifitas sehari-harinya, salahsatunya yaitu dalam berbisnis, jual-beli dan sebagainya. Namun, tidak semua dampak yang ditimbulkan oleh perkembangan tersebut merupakan hal yang bersifat positif, akan tetapi beberapa dampak negatif juga ikut berperan didalamnya. Contohnya seperti penipuan dalam jual-beli, pelaku bisnis yang semena-mena dalam berbisnis atau lebih tepatnya tidak memperdulikan etika dalam berbisnis.

2. Etika Bisnis dalam Pemasaran Syari'ah

Ada beberapa perbedaan antara Pemasaran Konvensional (Marketing) dengan Pemasaran Syari'ah (Islamic Marketing or Syari'ah Marketing) yaitu adalah dengan mengedepankan moral yang baik (akhlaq al-karimah) (Asnawi, 2017). Hal tersebut juga menjadi keistimewaan yang dipandang oleh masyarakat, karena moral merupakan peranan penting dalam pembentukan jiwa dan perilaku manusia. Seperti halnya alas an Allah Swt mengutus Nabi Muhammad Saw ke muka bumi ini adalah untuk menyempurnakan akhlak manusia (Hashim, 2012).

Praktik pemasaran syari'ah, tidak bisa lepas dari peranan Nabi Muhammad Saw sebagai panutan umat Islam, karena peranan sejati seorang Muslim terdapat pada Nabi Muhammad Saw yang mencerminkan 
hal-hal yang baik dalam setiap perkataan, perilaku, dan keputusan. Islam mewajibkan kepada manusia untuk memenuhi kebutuhan melalui cara-cara yang baik, termasuk dalam berbisnis. Jauh sebelum adanya pembahasan pemasaran modern tentang etika bisnis dan pemasaran, Islam sudah mengajarkan segala hal-hal yang berkaitan dengan etika dalam berbisnis dan pemasaran terlebih dahulu (Haque, Khaliq, \& Syeada, 2010) seperti halnya Rasulullah Saw memberikan contoh teladan kepada manusia untuk bertindak manusiawi tanpa melihat gender, ras, kepercayaan, warna kulit, asal-usul agama, bangsa, dan negara.

Di dalam buku Islamic Ethics: An Outline of Its Principles and Scope karya (Hashi, 2011) etika dalam berbisnis sangatlah penting, karena bersifat universal, unik dan berlaku untuk hal bersifat apapun, diantaranya sebagai berikut:

a. Etika Islam bersifat transcencental, artinya penentuan apa yang etis dan tidak etis, yang tepat dan tidak tepat serta benar atau tidak itu bersumber dari Allah Swt. Selain itu, sumber moralitas itu berasal dari perkataan Allah (kalam illahi), lain halnya etika konvensional yang baik buruknya disebabkan oleh dasar kemanfaatan dan keuntungan semata;

b. Sistem etika dalam Islam bersumber dari fitrah diri manusia;

c. Standar moral Islam mengajarkan keadilan universal dan kesetaraan manusia;

d. Tergantung pada niat diri manusia dan kekuatan keyakinan pada ayat-ayat Allah Swt, maka manusia akan dinilai etis atau bahkan sebaliknya;

e. Islam memberikan hak-hak manusia secara keseluruhan. Termasuk hak kebebasan dan kemerdekaan;

f. Islam menawarkan pendekatan sistem terbuka dalam etika, bukan self-oriented yang menimbulkan egoisme untuk memenuhi kepentingan pribadi demi memperoleh keuntungan;

g. Etika bisnis Islam tidak berorientasi pada keuntungan mayoritas dan minoritas yang tidak baik;

h. Nilai-nilai etika dalam Islam membawa ke-mashlahat-an manusia dan mencegah kemungkaran.

Jika dibandingkan dengan pendapat (Al-Qaradhawi, 1997), etika bisnis Islam itu meliputi beberapa hal sebagai berikut: 
a. Pada dasarnya diperbolehkan segala sesuatu;

b. Untuk membuat sah dan melarang adalah hak Allah Swat semata;

c. Melarang yang halal dan membolehkan yang haram merupakan perbuatan syirik;

d. Halal adalah boleh, dan haram adalah yang dilarang;

e. Larangan atas segala segala hal yang didasarkan atas sifat najis dan membahayakan;

f. Niat yang baik tidak bisa membuat yang haram itu diterima;

g. Menganggap yang haram sebagai halal adalah dilarang;

h. Barang haram terlarang bagi siapa pun;

i. Keharusan menentukan pilihan dan adanya pengecualian.

Selain beberapa pendapat diatas, (Hussnain, 2011) mengemukakan bahwa pelaku bisnis atau ekonomi yang sesuai dengan prinsip hukum Islam dan etika bisnis Islam adalah pelaku (marketer) yang teridentifikasi sebagai berikut:

a. Tidak tamak dan menjamin adanya keseimbangan dalam memenuhi permintaan;

b. Dalam praktiknya dilarang mencari keuntungan melalui cara yang tidak halal;

c. Batal transaksi adalah hal biasa dalam bisnis, sehingga harus bisa menerima;

d. Tidak ada pengecualian harga, harga berlaku untuk semua pelanggan dan sesuai mekanisme pasar, serta tidak ada diskriminasi kepada pelanggan.

Selanjutnya, (Zainal, 2012) berpendapat bahwa akhir dari orientasi pemasaran syari'ah adalah tidak hanya untuk meraup keuntungan duniawi saja, melainkan diharaokan mendatangkan manfaat dan keuntungan yang bersifat multiprofit. Untuk itu pelaku etika bisnis dalam pemasaran syari'ah harus memiliki Sembilan akhlak sebagai pondasi etika dalam berbisnis. Sembilan akhlak tersebut antara lain: (1) ber-taqwa atau memiliki kepribadian spiritual; (2) berkepribadian baik dan simpatik (shiddiq); (3) berlaku adil; (4) melayani pelanggan dengan rendah hati (khitmah); (5) selalu menepati janji dan menghindari kecurangan (tahfif); (6) jujur dan terpercaya; (7) tidak su'udon; (8) tidak ghibah; dan, (9) tidak melakukan suap (riswah). 
Dari beberapa penjelasan tentang ciri-ciri gambaran pelaku etika bisnis yang sesuai dengan hukum Islam diatas, bahwa etika yang diajarkan oleh Islam dalam cakupan universal termasuk bisnis, akan berdampak positif dan nyata jika dipegang teguh oleh para pelaku bisnis dan aktifitas ekonomi apapun. Selain itu, mempengaruhi hal positif lainnya dalam hubungan relasional jangka panjang dan lebih unggul dari kompetitor lainnya.

\section{Kunci Sukses dalam Pemasaran Syari'ah}

Persepsi yang kerap kali ditemukan oleh masyarakat bahwa pasar konvensional selalu lebih menguntungkan secara finansial dari pada pasar syari'ah atau pasar Islami yang disebabkan adanya bunga dan kelipatan keuntungan lainnya (Zainal, Djaelani, Basalamah, Yusran, \& Veithzal, 2018). Khususnya, pada era perkembangan Revolusi Industri 4.0 dan Society 5.0, tidak mudah merubah pola piker masyarakat untuk berpindah dari pemasaran konvensional ke pemasaran syari'ah.

Pemasaran syari'ah merupakan pemasaran yang bersifat nilai-nilai keislaman. Dalam arti lain, cara yang digunakan didalam pemasaran syari'ah mengedepankan prinsip-prinsip keadilan dan kejujuran, serta tidak nboleh bertentangan daripada prinsip-prinsip islam. Seperti halnya yang diajarkan oleh Rasulullah Saw bahwa kegiatan perdagangan harus berpegang teguh pada kebenaran, kejujuran, dan sikap amanah, namun tetap memperoleh keuntungan (Zainal, Djaelani, Basalamah, Yusran, \& Veithzal, 2018).

Berkaca dari sejarah, pemasaran syari'ah tidak bisa lepas dari sosok Rasulullah Saw yang telah memperkenalkan dan mengajarkan kepada kita tentang berdagang dan merupakan tokoh yang membawa perubahan besar bagi umat manusia. Seperti penjelasan dari (Zainal, Djaelani, Basalamah, Yusran, \& Veithzal, 2018) yang dikutip dari salahsatu penulis barat yaitu Michael H. Hart pada tahun 1978 yang kemudian direvisi tahun 1992 dengan judul The 100: A Ranking of the Most Influential Persons in History bahwa salahsatu took paling berpengaruh didunia ini adalah Nabi Muhammad Saw.

Adapun gambar empat sifat Rasulullah Saw dalam kehidupan umunya, dan khususnya dalam pemasaran syari'ah yang menjadi modal penting dalam memenangkan persaingan di era pemasaran modern yang 
dijelaskan oleh (Zainal, Djaelani, Basalamah, Yusran, \& Veithzal, 2018) sebagai berikut:

Gambar 3. Empat Sifat Rasulullah Saw sebagai Kunci Sukses dalam Pemasaran Syari'ah

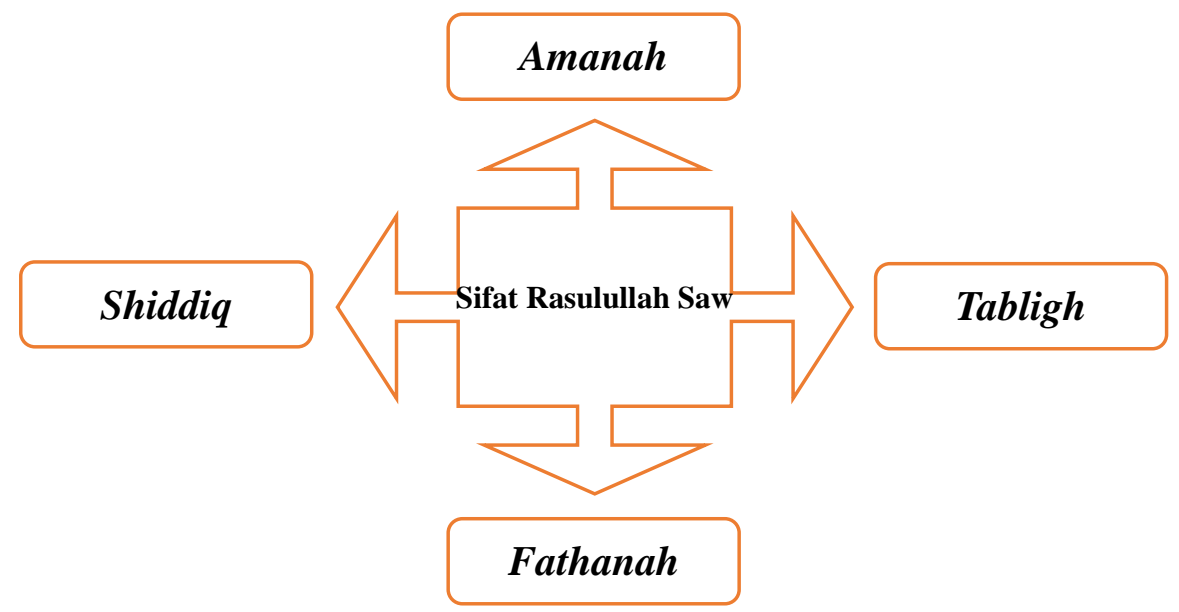

Maksud dari kata Shiddiq adalah benar/jujur. Penekanan kata Shiddiq tertera didalam Q.S. An-Nahl: 69 yang artinya: Dan barangsiapa yang mentaati Allah dan Rasul (Nya), mereka itu akan bersama-sama dengan orang-orang yang dianugerahi nikmat oleh Allah, yaitu: Nabi-nabi, para shiddiiqiin, orang-orang yang mati syahid, dan orang-orang saleh. Dan mereka itulah teman yang sebaik-baiknya". Menyampaikan segala macam kebenaran dan kejujuran merupakan salah satu sifat Nabi yang dimuliakan oleh Akkah Swt. Benar/jujur dapat diaplikasikan pada diri sendiri dan juga orang lain, karena sifat ini akan melahirkan sebuah keyakinan dan keberanian untuk menghadapi hal-hal yang mungkin tidak bisa diduga. Selain itu, sifat ini juga menjadikan sifat dari seorang pelaku bisnis dapat dipercaya dalam menjalankan aktifitas ekonomi oleh konsumen.

Menurut (Zainal V. R., 2012), kejujuran harus dibangun oleh seorang produsen atau pelaku bisnis sebagai modal keuntungan jangka pendek dan atau jangka panjang. Contoh dari pada sifat ini dalam menjalankan aktifitas ekonomi antara lain: (1) larangan tidak menepati janji yang telah disepakati; (2) larangan menutupi cacat atau barang yang dijual; (3) larangan membeli barang dari orang sebelum masuk pasar, dalam arti menghadang barang diperjalanan sebekum masuk ke pasar, karena pembeli berpotensi menuntut dengan harga yang lebih murah dari pasaran; dan (4) larangan mengurangi timbangan.

Selanjutnya adalah sifat amanah yang berarti dapat dipercaya atau 
mempunyai kredibilitas. Pada hakikatnya, amanah merupakan kata lain daripada jujur. Akan tetapi, amanah disini lebih kepada pola piker dan perasaan bahwa segala sesuatu yang dimilikinya adalah hanya titipan dan milik Allah Swt, karena seorang pelaku aktifitas ekonomi yang sesuai menurut Islam jika berbisnis akan merasa dirinya dilihat dan diawasi oleh Allah Swt (Ibrahim, Muhammad, \& Musani, 2008).

Sifat amanah mendorong seseorang untuk lebih bertanggungjawab terhadap dirinya sendiri, lingkungannya dan masyarakat sekitarnya, karena sifat ini akan berpengaruh terhadap kualitas hubungan seseorang dalam bermuamalah. Seperti halnya HR. Ahmad dan Abu Dawud yang dikutip dari (Sulaiman \& Zakaria, 2010) yang berbunyi: "Tunaikanlah amanat terhadap orang yang mengamanatimu dan janganlah berkhianat terhadap orang yang mengkhiatanimu".

Sifat amanah memiliki beberapa unsur yang kuar, salahssatunya adalah unsur dalam menepati janji (Zainal V. R., 2012). Sebagai pelaku aktifitas ekonomi diharusnya untuk memiliki unsur ketepatan dalam memberikan janji, karena akan berdampak pada kepuasan pelanggan, kepercayaan pelanggan, dan memperkuat hubungan jangka panjang. Selain itu, sebagai Muslim tidak diperkenankan untuk melakukan tidakan suap, memberikan komisi dan hadiah yang diharamkan, memakan riba, dan melakukan tindakan ke-dzalim-an untuk memenuhi sifat amanah tersebut.

Sifat ketiga adalah tabligh yang berarti menyampaikan. Akan tetapi dalam konteks ini, tabligh berarti komunikatif dalam menyampaikan informasi, objektif, dan ikhlas (Zainal V. R., 2012). Sifat ini merupakan gambaran personality dari seorang pelaku aktifits ekonomi (marketer), karena sifat ini melahirkan hal positif yang banyak disukai oleh pembeli, bayangkan jika menjadi seorang yang tidak komunikatif dalam menjalankan aktifitas ekonomi, pasti pembeli tidak akan datang. Islam mengajarkan sifat tabligh (komunikatif) kepada umat manusia tentu dengan ukuran yang tepat. Maksudnya adalah dengan standar yang tepat dan bisa diterima oleh masyarakat, seperti halnya mengajarkan untuk memberikn informasi yang berbobot dan akurat (tidak ditambah atau dikurangi), pengucapan dengan tutur kata yang baik dan sopan atau bisa disebut dengan bilhiqmah wa qoulan syadiidan (menggunakan bahasa yang tidak menggurui dan atau merasa paling benar). Didalam al-qur'an 
disebutkan dalan surat An-Nisa: 9 yang berbunyi: "Dan hendaklah takut kepada Allah orang-orang yang seandainya meninggalkan dibelakang mereka anak-anak yang lemah, yang mereka khawatir terhadap (kesejahteraan) mereka. Oleh sebab itu hendaklah mereka bertakwa kepada Allah dan hendaklah mereka mengucapkan perkataan yang benar".

Sifat keempat adalah fathanah yaitu cerdas/cakap, namun yang dimaksud disini adalah bijak dalam mengambil keputusan, khususnya dalam praktik bisnis atau pemasaran. Selain itu, bijak disini juga bearti tidak pernah putus asa dan kecewa, bahkan harus positif dalam menjalani proses aktifitas pemasaran (Zainal V. R., 2012).

Seorang pelaku bisnis yang sesuai dengan prinsip Islam seharusnya menganggap untung dan rugi dalam suatu aktifitas ekonomi menjadi hal yang lumrah. Jika rugi, jangan pernah menyesali terlalu dalam, dan jika untung, jangan berfoya-foya dan selalu bersyukur atas apa yang didapatkan. Namun, jika keempat sifat Rasulullah diaplikasikan dalam kehidupan sehari-hari apalagi dalam berbisnis, niscaya akan lebih banyak mendapat keuntungan, dan bahkan akan berlimpah. Seperti firman Allah Swt dalam Q.S. An-Nur: 37 yang berarti: laki-laki yang tidak dilalaikan oleh perniagaan dan tidak (pula) oleh jual beli dari mengingati Allah, dan (dari) mendirikan sembahyang, dan (dari) membayarkan zakat. Mereka takut kepada suatu hari yang (di hari itu) hati dan penglihatan menjadi goncang".

Dalam sifat fathanah, Islam menjelaskannya kedalam dua aspek yang penting dan berbeda, antara lain: (1) fathanah dalam aspek manajemen dan administrasi; dan (2) fathanah dalam menangkap orientasi pembeli (Zainal V. R., 2012). Pertama, contoh daripada aspek fathanah dalam manejemen dan administrasi adalah seperti pembukuan usaha yang rapi dan jelas, hal ini dimaksudkan untuk menjaga sifat shiddiq. Kedua, dalam aspek orientasi pembeli yaitu sebagai pelaku bisnis harus mengetahui kebutuhan dan keinginan konsumen agar bisa menyaingi perkembangan pasar yang ada. Selain itu, penampilan dari produk, pelayanan, persuasi, dan mengutamakan kepuasan pelanggan juga merupakan bagian dari apek orientasi pembeli.

\section{SIMPULAN}

Dari pemaparan di atas, dapat diambil kesimpulan bahwa sangat memungkinkan bagi para pelaku aktifitas bisnis untuk lebih 
memperhatikan etika dalam berbisnis dengan lebih mengoontrol diri dan mengatur strategi agar tidak dikendalikan oleh rasio akal pemikiran manusia saja, melainkan harus menggabungkan rasio akal pemikiran dan spiritual agar tercipta etika bisnis yang baik, seperti halnya membuat personality seorang marketer lebih mencerminkan sifat Rasulullah Swt yaitu shiddiq, amanah, tabligh, dan fathanah. Selain itu, pada dasarnya etika pemasaran yang berkembang dalam dunia modern sama dengan apa yang terjadi pada etika pemasaran syari'ah. Namun, secara substansial, etika pemasaran yang anut oleh konvensional lebih mengikuti rasio akal pemikiran manusia tanpa diimbangi spiritual yang berlandaskan al-qur'an dan sunnah.

Selanjutnya, peneliti meninjau dari segi metodologi yang sering digunakan oleh para akademisi ekonomi Islam dalam merumuskan konsep pemasaran Islam adalah integrasi ajaran Islam sebagai panutan pemasaran syari'ah dengan konsep pemasaran konvensional. Oleh karena itu, peluang untuk mengkaji pemasaran Islam lebih mendalam sangat terbuka luas karena secara konsep, masih banyak pendekatan-pendekatan lain yang bisa digunakan untuk meneliti hal tersebut untuk menghadapi perkembangan dinamis pasar modern.

\section{DAFTAR RUJUKAN}

Al-Qaradhawi, Y. (1997). Norma dan Etika Ekonomi Islam, terjemahan Zainal Arifin. Jakarta: Gema Insani.

Asnawi, N. (2017). Pemasaran Syari'ah: Teori, Filosofi, dan Isu-isu Kontemporer, Ed.1, Cet. 1. Depok: Rajawali Pers.

Haque, A., Khaliq, A., \& Syeada, I. J. (2010). Shariah Observation: Advertising Practices of Bank Muamalat in Malaysia. Journal of Islamic Marketing, Vol. 1, No. 1, pp. 70-77.

Hashi, A. A. (2011). Islamic Ethics: An Outline of Its Priciples and Scope. Revelation and Science, Vol. 01, No. 03 (1433/2011) 122-130.

Hashim, M. (2012). Islamic Perception of Business Ethics and the Impact of Secular Thoughts on Islamic Business Ethics. International Journal of Academic Research in Business and Social Sciences, Vol. 2, No. 3.

Hussnain, S. A. (2011). What is ISlamic Marketing. Global Journal of Management and Business Research, Vol. 11, Issue 11, Version 1.0 November. 
Ibrahim, M. F., Muhammad, M. Z., \& Musani, S. (2008). Islamic Marketing Concept in Business Based on Islamic Economics for Muslim Entrepreneurs. Prosiding Perkem III, Jilid 1 (pp. 110-117 ISSN: 2231-962X). Negeri Sembilan, Malaysia: Perkem III, Daya Tahan Ekonomi Negara: Dasar dan Strategi Pengukuhan Port Dickson.

Mumtaha, H. A., \& Khoiri, H. A. (2019). Analisis Dampak Perkembangan Revolusi Industri 4.0 dan Society 5.0 Pada Perilaku Masyarakat Ekonomi (E-Commerce). Pilar Teknologi: Jurnal Ilmiah Ilmu-Ilmu Teknik. Vol. 4, No.2. Diakses di http://pilar.unmermadiun.ac.id/ind.

Sulaiman, M., \& Zakaria, A. (2010). Jejak Bisnis Rasul. Jakarta: Noura Books (PT. Mizan Publika).

Zainal, V. R. (2012). Islamic Marketing: Membangun \& Mengembangkan Bisnis Dengan Praktik Marketing Rasulillah Saw. (Islamic Marketing: Establishing and Developing Business with Marketing Practices Rasulullah Saw). Jakarta: PT. Gramedia Pustaka Utama.

Zainal, V. R., Djaelani, F., Basalamah, S., Yusran, H. L., \& Veithzal, A. P. (2018). Islamic Marketing Management: Mengembangkan Bisnis dengan Hijrah ke Pemasaran Islami Mengikuti Praktik Rasulullah Saw. Jakarta: PT. Bumi Aksara. 